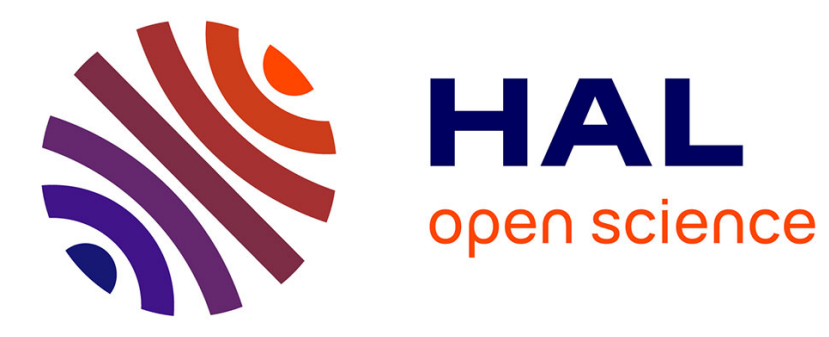

\title{
Information Access Assistant Service (IAAS)
}

Kiswendsida K. Kaboré, Florence Sèdes, Oumarou Sie, André Péninou

\section{To cite this version:}

Kiswendsida K. Kaboré, Florence Sèdes, Oumarou Sie, André Péninou. Information Access Assistant Service (IAAS). 8th International Conference for Internet Technology and Secured Transactions (ICITST 2013), Dec 2013, Londres, United Kingdom. pp.554-557, 10.1109/ICITST.2013.6750263 . hal-01202527

\section{HAL Id: hal-01202527 \\ https://hal.science/hal-01202527}

Submitted on 21 Sep 2015

HAL is a multi-disciplinary open access archive for the deposit and dissemination of scientific research documents, whether they are published or not. The documents may come from teaching and research institutions in France or abroad, or from public or private research centers.
L'archive ouverte pluridisciplinaire HAL, est destinée au dépôt et à la diffusion de documents scientifiques de niveau recherche, publiés ou non, émanant des établissements d'enseignement et de recherche français ou étrangers, des laboratoires publics ou privés. 


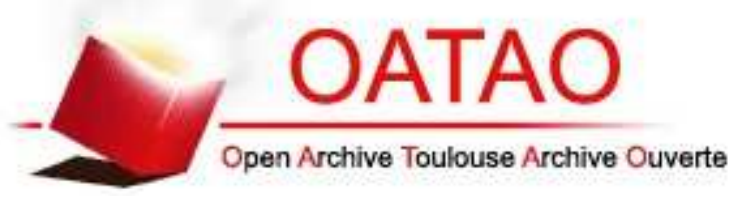

\section{Open Archive TOULOUSE Archive Ouverte (OATAO)}

OATAO is an open access repository that collects the work of Toulouse researchers and makes it freely available over the web where possible.

This is an author-deposited version published in : http://oatao.univ-toulouse.fr/ Eprints ID : 12832

Official URL: http://dx.doi.org/10.1109/ICITST.2013.6750263

To cite this version : Kaboré, Kiswendsida K. and Sèdes, Florence and Sie, Oumarou and Péninou, André Information Access Assistant Service (IAAS). (2013) In: 8th International Conference for Internet Technology and Secured Transactions (ICITST 2013), 9 December 2013 - 12 December 2013 (Londres, United Kingdom).

Any correspondance concerning this service should be sent to the repository administrator: staff-oatao@listes-diff.inp-toulouse.fr 


\section{Information Access Assistant Service (IAAS)}

\author{
Kiswendsida K. Kaboré \\ IRIT, SEA-UO, \\ Saaba BP 36 Burkina Faso \\ (226)76614605 kabore@irit.fr \\ Oumarou Sie \\ LTIC, SEA-UO \\ BP 7021 Burkina Faso \\ (226)70251849sie@univ-ouaga.bf
}

\author{
Florence Sèdes \\ IRIT \\ 118 Route de Narbonne 31062 Toulouse France \\ (33) 561556765 sedes@irit.fr \\ André Peninou \\ IRIT \\ 118 Route de Narbonne 31062 Toulouse France \\ (33) 561556765 peninou@irit.fr
}

\begin{abstract}
With the great diffusion of multimedia information on the web, plenty of solutions are proposed to solve the web users' cognitive overload. Despite the multitude of solutions, the web users are still looking for more and more simple assistant in web using. In this paper we present an information adaptation system using characteristics of the user. Our work aims improving access to information through recommendations made by system users with access to information. After introducing the concepts and mechanisms used by our system, we compare it with other systems in order to show the originality of our ideas.
\end{abstract}

\section{Keywords- user group customization; web services}

\section{INTRODUCTION}

With the development of the web, today's world is characterized by an abundance of knowledge to the point that access to relevant information for the user faces to a cognitive overload. The knowledge contained in tanks (of knowledge) or not, is now provided by dynamic adaptive hypermedia systems where the learner as a user of these systems needs to be directed. To satisfy this need of the user, the interaction between the user and the system was most often the preferred means for systems to acquire information to improve qualitatively the results of queries. In this context, our work aims to use user input to give him greater satisfaction to his needs. This work therefore is a response to the user's need to be referred to the relevant information.

Our work may find applications in various fields such as elearning, access to document archives or in the case of online libraries.

In what follows, we describe an Information Access Assistant Service (IAAS). This service collects notices given by users. Then it uses these notices to provide recommendations for filtering information.

\section{DEFINITION OF THE WORK'S FIELD}

For this study, we are in an access background information where the user launches queries and get back a list of documents and we want to allow the user to get to his requests environment relevant documents by relevance opinions given by other users. We believe that users are grouped into user groups with preferences common information needs. The opinions of relevance will be given with respect to these groups. These notices of relevance will be used to provide access to information to the user customization.

In general, it is therefore the result of the work already done in our research team. And to do this, we use the recommendations of documents to groups of users by users to provide personalization features. Taking the example of the access to information process defined in the upstream and downstream [1], our service only intervene in downstream to provide an alternative treatment to income as indicated on the diagram below.

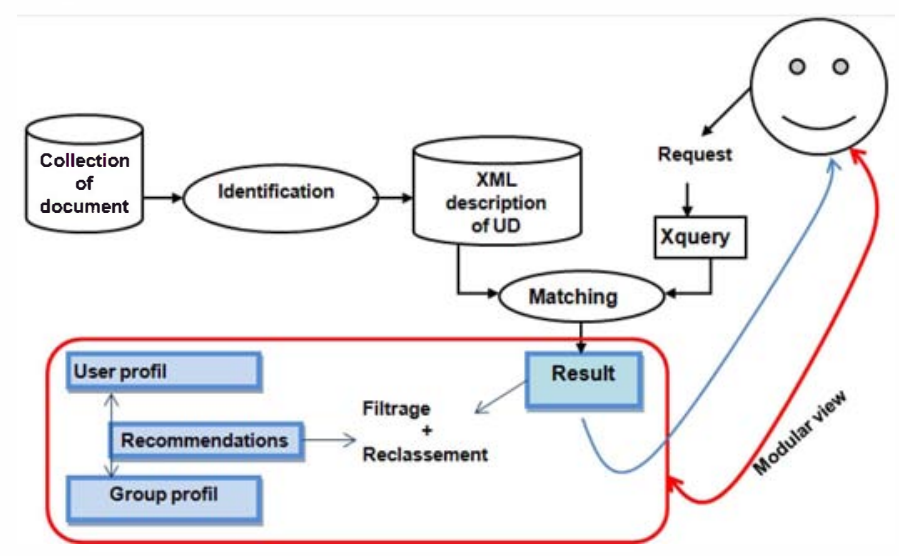

Figure 1. Delineation of Area of Intervention

As indicated in the framed part of the image above, our service will help take the result of the user query and interact with the user to offer a personalized view of the collection. We assume that users and groups are created. The profiles will be enriched by notices of pertinence, which will allow to make recommendations and to perform filtering on the result. Furthermore, we consider clusters where each user is asked to recommend parts of documents that match the course of his access to documents. 
In the following, we describe the support service for access to documents in detail through the presentation of personalization mechanisms, some models and implementation leading to the implementation of IAAS.

\section{STATE OF THE ART}

In this section, we present some similar work we have noted throughout the literature and we make a comparison with IAAS to externalize the differences with our work.

\section{A. Related work}

Recommender systems: Many studies are conducted within the framework of recommender systems. We can cite the work of [2] made recommendations for documents. His work is based on the use of the ontology.

Multimedia Systems: In the area of adaptive systems, many studies are conducted on various aspects. While [3] plays on the dynamic re-engineering the appropriate hypermedia user [1] uses the focus of the user to customize a list of documents in the light of the user. Many studies such as [4] use the pervasive aspects of multimedia systems to adapt according to the user access the content.

Personalization techniques: The literature shows that there are many works that use a variety of techniques but different from ours. We can cite the work of [5] which uses the fusion of search results to the user customization. The result of the fusion is divided into groups before being revealed to the user.

In the work of [6], the interaction for social navigation is used to make recommendations navigation paths to access the news groups. [7] uses the user behavior, organizes data mining, and after the discovery of knowledge, recommendations of lessons are made for learners of E-learning. Also in the field of E-learning, [8] uses the Semantic Web and dynamic repository to perform the personalization of learning materials in a distributed environment.

\begin{tabular}{|c|c|c|c|}
\hline & \multicolumn{2}{|c|}{ User } & \multirow[b]{2}{*}{$\begin{array}{l}\text { Mechanism of } \\
\text { Customization }\end{array}$} \\
\hline & $\begin{array}{l}\text { Characteristics } \\
\text { used for } \\
\text { Customization }\end{array}$ & $\begin{array}{l}\text { Information returned } \\
\text { to user after } \\
\text { Customization. }\end{array}$ & \\
\hline $\begin{array}{c}{[\text { Morris, 2008] }} \\
{[5]}\end{array}$ & $\begin{array}{l}\text { Objectives of the } \\
\text { group. }\end{array}$ & $\begin{array}{l}\text { Important data deemed } \\
\text { highlighted. }\end{array}$ & $\begin{array}{l}\text {-Fusion of the result } \\
\text {-distribution results in groups } \\
\text {-Highlighting groups }\end{array}$ \\
\hline $\begin{array}{ll}\text { Barra, } & 2008] \\
& {[6]}\end{array}$ & $\begin{array}{l}\text { Interactions } \\
\text { Access Group }\end{array}$ & $\begin{array}{l}\text { Recommendation of } \\
\text { Social navigation path. }\end{array}$ & $\begin{array}{l}\text {-Navigation } \\
\text {-Recommendations } \\
\text { - Social Navigation path. }\end{array}$ \\
\hline $\begin{array}{c}\text { Kristofic, 2005] } \\
{[7]}\end{array}$ & Student behavior & $\begin{array}{l}\text { Recommendation of } \\
\text { lessons. }\end{array}$ & $\begin{array}{l}\text { - Dig-data } \\
\text {-Knowledge Discovery } \\
\text {-Recommendation of lesson }\end{array}$ \\
\hline $\begin{array}{cc}{[\text { Dolog, }} & 2004] \\
& {[8]}\end{array}$ & $\begin{array}{l}\text { Situation in the } \\
\text { custom-web- } \\
\text { environment }\end{array}$ & -Custom Supports & $\begin{array}{l}\text {-Supports semantic } \\
\text {-Distributed environment } \\
\text {-Semantic Web } \\
\text {-E-Learning } \\
\text {-Dynamically Repository }\end{array}$ \\
\hline $\begin{array}{r}\text { Lotfi 2011] } \\
{[9]}\end{array}$ & User traces. & Various Support & M-Trace \\
\hline $\begin{array}{c}\text { [Ginon 2013] } \\
{[5]}\end{array}$ & User traces. & Various Support & M-Trace \\
\hline
\end{tabular}

Figure 2. Table N01 - Comparison Chart adaptive systems

Some recently works [9] and [10] focus on using traces of users to provide adaptation, recommendations and other assistances to users. Nowadays, the M- traces are used in many applications especially in the geomantic. However the Mtraces are not the focus of this study.

\section{B. Specifications of IAAS}

All the means mentioned above can make recommendations and adaptations in many fields including hypermedia. However, they all differ from what is done in IAAS. Firstly, in IAAS the recommendations and adaptations of list of documents are made to group of users by users. In opposite the systems in figure 2 use other criteria such as the user's interests. Secondly the manner to build the relevance of documents is simple and participatory, which is not the case mentioned above in general,

In the section below, we present the mechanisms of customization used by IAAS.

\section{MECHANISMS FOR CUSTOMIZATION IN IAAS}

\section{A. General Mechanism}

We designed a support service for personalized access to information. This service is described in the image below.

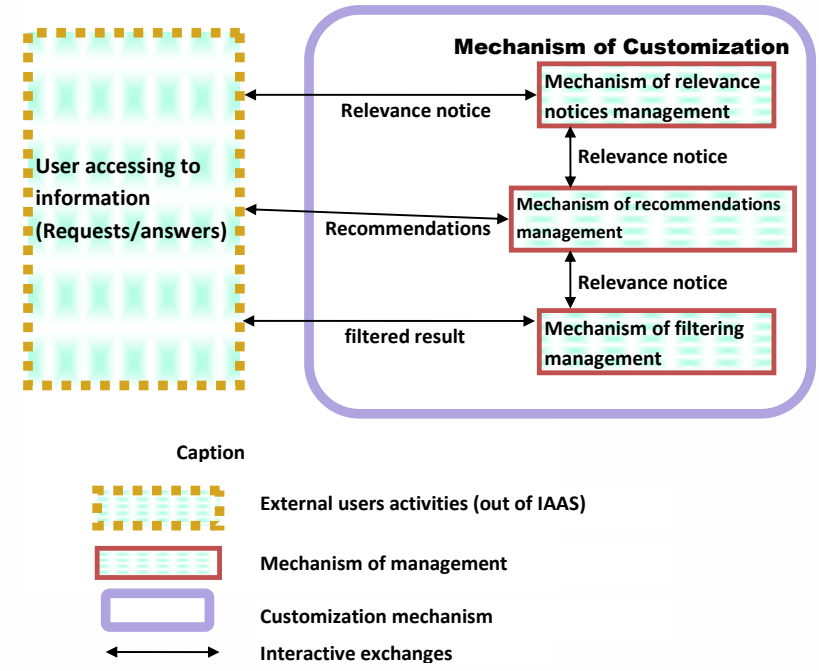

Figure 3. Support Service for Information Access Assistant Service (IAAS )

In general, we consider the activity of a user consisting largely to access to information by proceeding from successive Requests/Responses with information systems. This activity which is shown in the diagram above is not itself the subject of our work. However, this activity will generate signals to request access to information that we will use.

In addition to the answers that the user will receive information during system activity, we want to propose an additional service to help him to access earlier to the information he needs.

The customization mechanism specified in the image will provide the user with recommendations of documentary units and a filtered result. The customization mechanism will work in three parts: management mechanism opinions, GM 
management recommendations and filtering mechanism. In the next part, we present these management mechanisms.

\section{B. Relevance notice, filtering and recommendation}

After presenting our understanding of the relevance notices, we present a mechanism for the collection of these notices.

\section{1 . Notion of relevance notice}

As mentioned above, users will appreciate IAAS documentary units during their documents consulting session. These are assessments that we refer to as the "relevance notice". In the literature, the term "vote" is often used for recommender systems. In our work, we keep the term relevance notice.

The term "relevance feedback" is often used for certain access to information systems. This term is appropriate when assessing the relevance is relative to the user's request, which is not the case in our work. We do not use this term because in our work, the assessment of relevance made by the user is made independently of its requests.

We consider that a notice of relevance is a recommendation of documentary units, made by a user to a user thematic group. We consider that the fact he is himself a member of that group or not, does not affect the relevance of the assessment.

A notice is a 3-Tuple $A=(U D, G, a)$. UD is documentary unit, a group $G$ and $P$ a relevance weight . In giving his notice $A=(\mathrm{UDi}, \mathrm{Gj}, \mathrm{a})$ a user expresses the fact that for him, the documentary unit UDi is relevant to the thematic group $\mathrm{Gj}$.

Notice A has an integer value ' a' included between 1 and $10: 1$ for relevant and appropriate medium for 5,10 very relevant : we call this value "value of the relevance". A notice of relevance will match one group and one resource.

\section{2 . Collection of relevance notices for groups}

Each time a user will access a document, the collection mechanism will allow him to give his opinion on the relevance of parts of the document. So, considering that throughout the information access system we have a total of $n$ user's groups and $\mathrm{m}$ UD (documentary units), each of the $\mathrm{n}$ groups can have a number of recommended separate document units between 0 and $\mathrm{m}$. Similarly, each of documentary units may be recommended for a number of distinct groups between 0 and $\mathrm{m}$. It should also be noted that many users will eventually pass a documentary unit UDi for the same group G, we call weight of recommendation $=\mathrm{Pk}$ ( UDiGj $)$ all of these notice. When no notice is for a group, we consider that the weight of recommendation for each Documentary Units is equal to 0 :

$$
\mathrm{Pk}(\mathrm{UDiGj})=0
$$

When a number of recommendations is made UD to the same group, the resulting weight is the sum of the weights:

$$
\mathrm{Pk}(\mathrm{UDiGj})=\operatorname{sum}((\mathrm{UDi}, \mathrm{Gj}, \mathrm{a}))
$$

We summarized by the following algorithm:

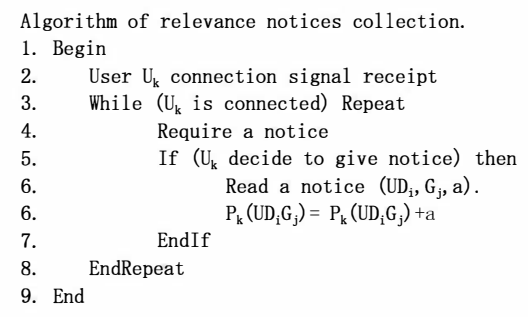

Figure 4. Algorithm

Should it be noted that documentary units may include but it does not play on the record opinions. A notice is registered individually for the recommended UD.

In sum, the notice shall be recorded in the relevant group's profiles. It will therefore be an enrichment for the group's profiles. The weight of recommendation will be used by the management mechanism recommendations.

\section{IMPLEMENTATION}

To realize the IAAS system, we created models, the two most important are the model of documents and the user model we present in below.

\section{A. Model of documents}

In our work we consider an area characterized by a collection of documents in which the description of documentary units is performed in a database of document descriptors. The user queries the information system by keywords. We consider the query result as a list of references to literature units.

The use of documentary units allows users to easily access accurate to parts of documents.

A documentary unit is part of a document that may be an area image, audio segment, a video sequence or a textual unit. For example, textual unit may be a chapter, section, paragraph or any other text. The class diagram in Figure 5 defined describes a documentary unit used in the field.

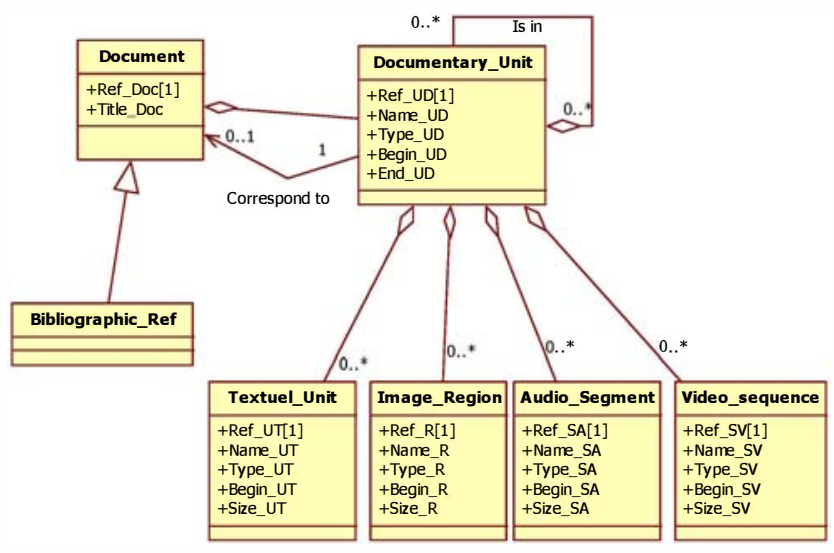

Figure 5. Meta-model of documents 
A document will be uniquely identified by a reference (Ref_Doc) and title. Moreover, it will be associated with its classical references (Author, date of publication, Publisher, etc..). The document will be considered as a set of documentary units and is itself considered as a full-fledged documentary unit (Relationship "Correspond à").

A Documentary Unit (DU) will be identified by a unique reference (Ref_UD), a start line in the document (Begin_UD) and another end (End UD). The UD has a name (optional) and type (UT = Textual Unit, Image, Audio, Video, $\mathrm{M}=$ Mixed). A UD can be composed of several other UD. This composition will help to refine the granularity of control UD.

A UD is considered as a set of units of text, images, sound and video. The latter will be characterized by their reference $($ Ref *), name (optional), type, start line, and size. The Type_UT attribute can take the values (Part, Chapter, Paragraph, Text). Size_UT represents the number of lines of text.

\section{B. Model of Users Profile}

The help for access to information service will use the characteristics of users and their groups to manage and implement the recommendations filtering. These features are grouped across the group profile and user profile.

Figure 6 shows the user model used by our service with access to information.

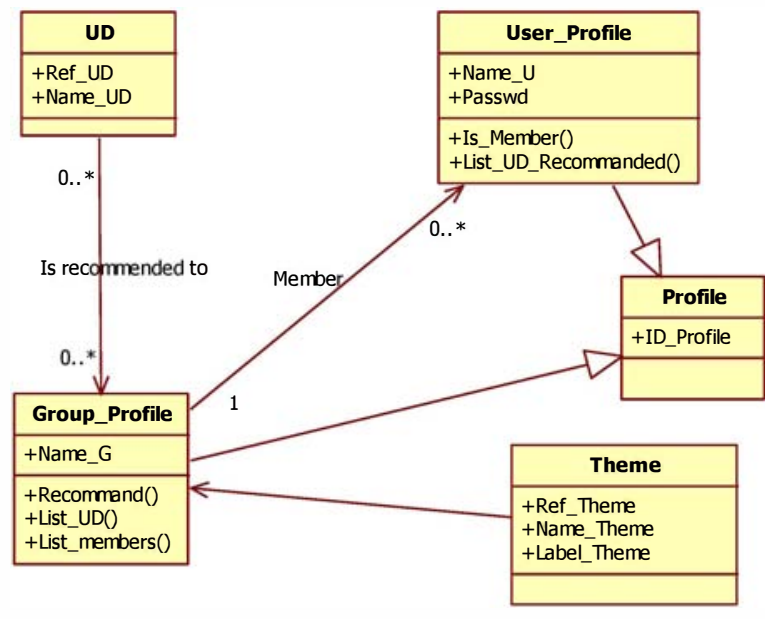

Figure 6. Canonical model of user profile management recommendations

\section{We have two types of profiles:}

(1) The user profile that will bring together all the information about the user. This profile will be identified by Name_U. From this profile, it will be possible to access the user group and the list of documents recommended to this group. A user will be in one and only one group.

(2) The group profile will allow us to gather information about user groups. This profile is identified by its name (Name G) and will allow us to make recommendations documentary units (the Recommend ( ) method), as well as access to the list of UD recommended to this group (list UD()) and the list of members of this group (List_members( )).

The thematic groups: Group profiles are associated with one and only one predefined theme. The class theme has an identifier (Ref_Theme) and will have a short theme name (Name_Theme) and Long (Label_Thème).

The documentary unit (DU) is used to manage the recommendations. Reference (Ref_UD) and name (Name_UD) of UD sufficient to manage the recommendations. A UD may be recommended several times to groups that in turn can get recommendations from one or more UD.

This way of representing allows flexibility in the management recommendations.

\section{CONCLUSION}

In this paper, we have presented the IAAS system to collect notice of relevance and use them for recommendations and adaptations. This idea offers innovative practices to assist and guide the user in the search for information and get access to relevant information at the earliest.

In the continuation of our work, we intend to keep on IAAS evaluation to enable it to improve. We will compare the achievements of the methods used by IAAS systems with those of systems based on M-trace.

\section{REFERENCES}

[1] A. C. Zayani, Contribution à la définition et à la mise en œuvre de mécanismes d'adaptation de document semi-structurés, May 192008.

[2] M. Brut, Ontology-based modeling and recomandation techniques for adaptive hypermedia systems, Thesis of Alexandru Ioan Cuza University, Iasi, Romania Faculty of Computer Science, September 2008.

[3] I. Amous, Méthodologies de conception d'applications Hypermédia Extension pour la réingénierie de sites web, Thèse de l'Université Paul Sabatier de Toulouse, December 2002.

[4] G. B. Hagos, Accès et adaptation de contenu multimédia pour les systèmes pervasifs, Thèse de l'Institut Nationale des Sciences appliquées de Lyon, September 2006.

[5] M. R. Morris, J. Teevan, S. Bush, Enhancing collaborative Web search with personalization : Groupization, Smart Splitting, and Group HitHighlighting. In ACM Conference CSCW'08, November 8-12, 2008 , San Diego, California, USA. Copyright 2008 ACM 978-1-60558-007

[6] M. Barra, D. Malandrivo, V. Scarano, "Common" Web paths in a group adaptive System; In ACM Conference HT'03, August 26-30, 2003, Nottingham, United Kingdom. ACM 1-58113-704-4/03/0008

[7] A. Kristofic, M. Bielikova, Improving adaptation in Web-based educational hypermedia by means of knowledge discovery. In ACM Conference. HT'05, September 6-9, 2005, Salzburg, Austria. ACM 1595931686/05/0009

[8] P. Dolog, M. Sintek, Personalization in distributed e-learning environnements. In ACM Conference. WWW2004, May 17-22, 2004, New York, New York, USA. ACM 1581139128/04/0005

[9] L. S. SETTOUTI, Systèmes à Base de Traces Modélisées : Modèles et Langages pour l'exploitation des traces d'Interactions, January 2011.

[10] B. Ginon, S. J. Daubias, et P. A. Champin, Mise en place d'un système d'assistance personnalisée dans une application existante, Liris. 2013 